\title{
1985 MRS Fall Meeting Preview
}

\section{Technical Symposia, Equipment Exhibit, 14 Short Courses, Job Placement Center}

The annual MRS Fall Meeting in Boston will take place December 1-6, 1985, and will be the largest MRS conference and exhibit to date. A total of 22 technical meetings will focus on a number of successful MRS symposia series as well as feature two new topical areas never before addressed at an international MRS conference.

The popular equipment exhibit, instituted at last year's Fall Meeting, will again be held throughout the week at convenient times for meeting participants to browse without missing out on symposia sessions. This year the exhibit will feature approximately 100 displays by manufacturers, suppliers and distributors of scientific instruments and services. The exhibit is operated for the Society by the American Institute of Physics, which will also manage the Job Placement Center during the week. This service, open from 9:00 a.m. to 5:00 p.m., Tuesday through Thursday, is a convenient way for prospective employers and scientists to meet face to face and discuss career objectives and job opportunities, conveniently and confidentially.

A special session on Monday evening will recognize the winner of the Arthur Von Hippel Award, the Society's most prestigious honor, and winners of the Graduate Student Awards. Wednesday evening, Gerald Yonas, chief scientist and acting deputy director, Strategic Defense Initiative Organization, will present the Plenary Address. Dr. Yonas will discuss "Materials for SDI."

Wrapping up this intense week on the most important materials developments to date are 14 short courses on various topical interest areas which will run on Friday and Saturday. Registration for the courses is limited, and early registration is encouraged.

Review the following schedule of events and highlights, and register now to be in Boston with your colleagues from around the world.

\section{Exhibitors at 1985 MRS Fall Meeting}

\section{(as of August 9, 1985)}

Academic Press
AG Associates
Alcatel Vacuum Products
Andonian Cryogenics
Amplifier Research
Atomika
Bio-Rad SMS
Blake Industries
Callery Chemical Co.
Cameca Instruments
Ceramaseal
Cryomagnetics
Eaton Corp.
Edax International
EG\&G Princeton Applied
Research
Charles Evans Associates
Gatan
Gaertner Scientific
GEC Avionics
General Ionex
Granville-Phillips
High Voltage Engineering
Europa BV
ICl Americas

Academic Press

AG Associates

Alcatel Vacuum Products

Andonian Cryogenic

Atomika

Bio-Rad SMS

Blake Industrie

Callery Chemical Co.

Ceramaseal

Cryomagnetics

Eaton Corp.

International

Research

Charles Evans Associates

Gatan

GEC Avionics

High Voltage Engineering

ICl Americas
Instruments SA

International Scientific Instruments

Ion Tec

Janis Research Co

Jeol USA

Keithley Instruments

Kimball Physics

Lake Shore Cryotronics

Lecroy Research Systems

Kurt J. Lesker Co

Leybold-Heraeus Vacuum

Products

Materials by Metron

Micron Optics

Microscience

MKS Instruments

MMR Technologies

National Electrostatics Corp.

Neslab Instruments

Netzch

NGS Associates

North Eastern Analytical

Oriel

Oxford Instruments NA
Perkin-Elmer Physical Electronics

Philips Electronic Instruments

Photon Technology International

Plenum Publishing

Physicon

Physitec Corp

Polymer Labs

Princeton Gamma-Tech

Questek

Rigaku

Rudolph Research

Semiconductor Processing Co.

Sohio Engineered Materials Co.-

Carborundum

South Bay Technology

Spectramass

Spire

Structure Probe/SPI Supplies

Surface Alloys Corp.

Surface Science Labs

Tamarack Scientific

Themionics Labs

Tracor Northern

UHV Instruments

VG Instruments 
Beam-Solid Interactions and Phase Transformations (Symposium A) December 2-4 (Monday-Wednesday) Chairs: H. Kurz, Technical University Aachen; G. L. Olson, Hughes Research Laboratories; J. M. Poate, AT\&T Bell Laboratories

Approximately 76 oral and poster presentations will focus on laser-solid surface interactions, phase transitions and ion-solid interactions, laser-induced melting and exitation of semiconductors, laser-induced phase transformations in carbon and metals, ion beam-solid interactions, ion beam mixing and metastable phase formation. Some sessions are joint with Symposium D. Invited speakers include: N. Bloembergen, C. V. Shank, H. Walther, Y. R. Shen, W. L. Brown, D. Turnbull, J. S. Williams, J. W. Mayer, M. O. Thompson, A. M. Malvezzi, G. Braunstein, B. Stritzker, R. G. Elliman, F. W. Saris, J. A. Knapp.

\section{Rapid-Thermal Processing}

(Symposium B)

December 2-6 (Monday-Friday)

Chairs: T.O. Sedgwick, IBM T. J. Watson Research Center; T. E. Siedel, J. C.

Schumacher Co.; B.Y. Tsaur, MIT Lincoln Laboratory

Approximately 59 papers will address implanted dopant activities and diffusion in silicon, defects and microstructure, equipment and device applications, rapid thermal processing for VLSI processing (panel discussion), silicides and oxides, compound semiconductors. Invited speakers include: A. E. Michel, S. J. Pennycook, D. M. Maher, S. R. Wilson, P. K. Vasudev, F. M. d'Heurle, S. J. Pearton.

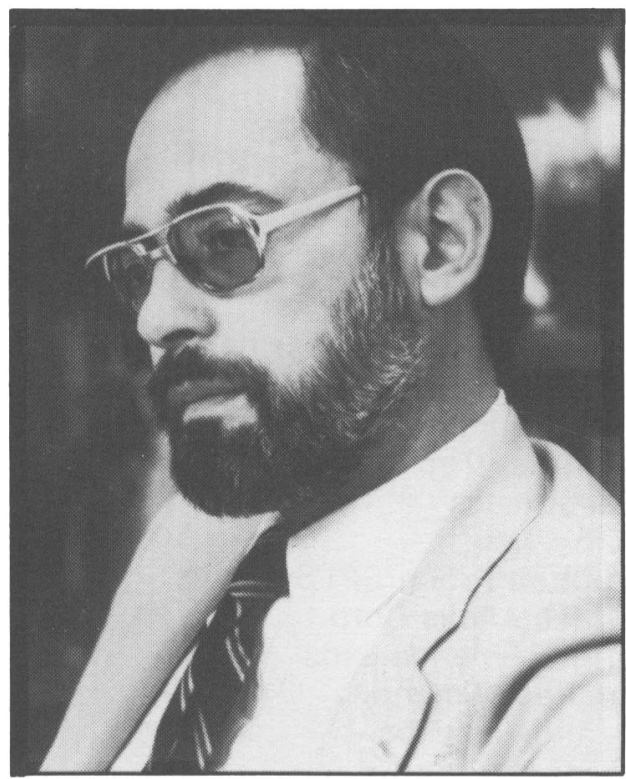

Plenary Speaker Gerald Yonas, Strategic Defense Initiative Organization

\section{TRANSPORTATION TO FALL MEETING}

CONVENTION AIRFARE

DISCOUNTS

American Airlines is offering MiRS members exclusive Meeting Saver fares equal to any American Airlines special promotional fare for which you may qualify or $35 \%$ discount off day coach fare, whichever is lower and in effect the date tickets are purchased. This exclusive Meeting Saver fare waives the Saturday night stay and is valid though the MRS Services desk for round trip domestic travel on American Airlines. Tickets may be purchased up to seven days prior to departure

RESERVATIONS:

Call the MRS Services desk of American Airlines weekdays 9:00 a.m. to $5: 30$ p.m. California time at (800) 6244868 (in California) or (800) 334-4331 (in Continental U.S.) Give the travel specialist the special MRS file number, S-7237. Your reservations on all airlines will be confirmed including connecting and round trip flights and your tickets sent to you directly. The

\section{Semiconductor-on-Insulator and Thin} Film Transistor Technology (Symposium C)

December 2-6 (Monday-Friday)

Chairs: A. Chiang, Xerox Palo Alto Research Center; M. W. Geis, MIT Lincoln Laboratory; L. Pfeiffer, AT\&T Bell Laboratories

Approximately 67 papers will focus on crystal growth and zone melting, epitaxy and SOS, implanted insulator, porous silicon, characterization of SOI thin films, polysilicon device and TFT, SOI devices and circuits/novel structures. Invited speakers include: K. A. Jackson, H. I. Smith, P. K. Vasudev, H. Ishiwara, D.J. Dumin, P. L. F. Hemment, H. W. Lam, J. M. Gibson, C. R. M. Grovenor, N. M. Johnson, H. Shichijo, B.-Y. Tsaur, D. W. Greve, T. Enomoto, M. S. Wrighton, R. H. Baughman.

\section{Beam-Induced Chemical Process}

(Symposium D)

December 2-6 (Monday-Friday)

Chairs: R. J. von Gutfeld, IBM T. J.

Watson Research Center; J. E. Greene, University of Illinois; J. Schlossberg, Air Force Office of Scientific Research

Approximately 66 papers will address lasersolid and surface interactions, phase transitions and ion-solid interactions, metal depositions, metal and semiconductor depositions, beam depositions, beam-induced etching, etching and product analysis, dynamics of beam surface interactions, VLSI and related applications. Some sessions are joint with Symposium A. Invited speakers include: $\mathrm{N}$. special discount Meeting Saver fare is available for MRS members through a special arrangement with American River Travel in Sacramento, California.

SPECIAL FEATURES:

When you make your flight reservations, you may order special diet entrees or any of seven American Traveler meals. American River Travel specialists will reserve the seat you choose-window, aisle, smoking or no-smoking - and help you confirm car rentals. At the airport, they will issue round trip boarding passes so you can skip check-in on your way home.

LOCAL TRANSPORTATION:

Shuttle service from Logan Airport to the Boston Marriott Hotel/Copley Place and The Westin Hotel departs every half hour from the designated shuttle stop in front of each terminal. The cost is $\$ 6$. Cab fare ranges between $\$ 10$ and $\$ 15$. Parking is available adjacent to both hotels at a cost of $\$ 12$ per day.

Bloembergen, C. V. Shank, H. Walther, Y. R. Shen, W. L. Brown, D. Turnbull, J. S. Williams, J. W. Mayer, C. R. Jones, M. E. Gross, Z. Yu, R. M. Osgood, J.-E. Sundgren, G. H. Chapman.

Thin Films-Interaces and Phenomena (Symposium E)

December 2-6 (Monday-Friday)

Chairs: R. J. Nemanich, Xerox Palo Alto Research Center; P.S. Ho, IBM Watson Research Center; S. S. Lau, University of California

Approximately 149 oral and poster presentations will address silicide formation and properties, epitaxial layers, reaction $\mathrm{ki}$ netics, ion mixing, Schottky barriers, epitaxial silicide, ion-beam mixing, interface characterization, contact to III-V's, compound semiconductor interfaces, VLSI technology and packaging, growth and analysis, oxides and nitrides. Some sesions joint with Symposium $H$. Invited speakers include: G. W. Rubloff, O. Bisi, I. Ohdomari, L. J. Chen, L. J. Schowalter, T. P. Smith, F. W. Saris, E. S. Yang, J. C. Hensel, R. T Tung, P. S. Ho, J. W. Mayer, S. Furukawa, T. S. Kuan, L. J. Brillson, A. K. Sinha.

\section{Transport and Excitations in Polymers} (Symposium F)

December 2-6 (Monday-Friday)

Chairs: T. Venkatesan, Bell

Communications Research, Inc; $E$.

Kramer, Cornell University; $R$. H.

Baughman, Allied Chemical Corporation

Approximately 92 oral and poster papers 